\title{
Fatigue Life Analysis of Steel Riveted Rail Bridges Affected by Corrosion
}

\author{
Martin Macho (D), Civil Engineer; Pavel Ryjáček, Civil Engineer, Czech Technical University in Prague, Prague, Czech Republic; \\ Jose Matos ㅁ, Civil Engineer, University of Minho, Campus Azurem, Guimaraes, Portugal. Contact: jmatos@civil.uminho.pt \\ DOI: $10.1080 / 10168664.2019 .1612315$
}

\begin{abstract}
Decades-old steel bridges have to endure an unfavourable environment that causes the ageing and deterioration of material properties. Moreover, railway bridges in particular are exposed to a large number of stress ranges that may lead to fatigue damage. The combination of both phenomena has a significant impact on the condition of bridges and their remaining service life. In such cases, appropriate maintenance or even removal of the deteriorated structure is necessary; however, a lack of funds often makes this difficult. The subject of this paper is the development of methodology for the assessment of remaining service life of existing steel bridges considering the fatigue and corrosion effects. Using MATLAB ${ }^{\circledR}$ software, a program for the prediction of the remaining fatigue life has been developed. The results of earlier experiments and numerical simulations were integrated into this tool. Various scenarios regarding the future maintenance of bridges were included in the program, thus making it possible to calculate the remaining service life of bridges, including corresponding costs. The second half of the paper presents a case study demonstrating the application of the methodology and the calculation program.
\end{abstract}

Keywords: fatigue life; corrosion; steel bridges; stress spectrum; bridge maintenance

\section{Introduction}

\section{Fatigue Load Effects}

The service life of many steel bridges in the Czech Republic, and in many other countries, is close to their expected lifetime and therefore assessment of the current state of such bridges needs to be carried out. In particular, railway bridges, which are known for their permanent resistance to heavy movable loads, are exposed to large stress ranges that may lead to fatigue damage. However, diagnostic methods for existing riveted bridges are limited. Several documents containing background to the assessment of fatigue life of riveted bridges are available. Assessment procedures and detail categories for riveted connections of steel bridges are stated in the International Union of Railways publication UIC 778-2-R. ${ }^{1}$ This document considers three groups of significant fatigue-sensitive details of riveted connections. Fatigue strengths of the most common riveted construction details are also available in Ref. [2].

\section{Corrosion Effects}

The corrosion process of steel is affected by many factors, such as the kind of steel and surface protection; environmental impact; and the presence of pollutants, cracks and stresses. The loss of material may result in a reduction in the cross-sectional area and thereby increase the stress level for a given load or increase the stress range for cycling loads. In addition, it can lead to a reduction in the buckling resistance of elements or the initiation of fractures. In general, the loss of cross-sectional area results in a decrease in geometric parameters such as the moment of inertia and radius of inertia.

For the assessment of existing steel members, the loss of material may be taken into account using corrosion models. Corrosion models depict the dependence of corrosion loss on time. Many types of models have been developed. ${ }^{3}$ Individual types of corrosion models differ according to the various mathematical functions that describe the development of corrosion loss over time, the various corrosive environments that are considered (rural, urban, etc.) and the various types of steel material.

\section{Combination of Fatigue and Corrosion Damage}

The influence of fatigue and corrosion on the behaviour of riveted connections has been the subject of much experimental and numerical research. ${ }^{4-6}$ Laboratory tests ${ }^{7}$ show that corrosion has a negative impact on the fatigue behaviour of steel riveted connections. As a result of the corrosion process, the surface of steel members becomes rough and the stress distribution changes. The fatigue life of test specimens affected by corrosion is shorter and fatigue cracks occur earlier in comparison to uncorroded elements. The change in length of the fatigue life of corroded members may be expressed as a change in detail category. The detail category becomes worse with increasing corrosion loss.

At present, there are not enough methods available for assessing steel bridge structures affected by degradation and corrosion. The methods used for the assessment of bearing capacity are based on the methods used to assess new constructions. Consideration of corrosion is not sufficiently defined in structural analysis, for either static or fatigue capacity. To solve this problem, only a small amount of background is available to structural engineers. For example, the approach set out in UIC $778-2-\mathrm{R}^{1}$ is based on the application of a partial safety factor, the value of which depends on the state of the components in terms of corrosion. The consideration of degradation for assessing bridges is also stated in Standards Council of Canada code CAN/CSAS6-06. ${ }^{8}$ Chapter 14 of this bridge design code, together with Ref. [9], recommends how to take into account the effects of corrosion on fatigue resistance, using a pitting factor $K_{\mathrm{p}}$.

For this reason, based on previous research, ${ }^{7}$ the aim of the present paper is to develop a methodology that takes into account both fatigue and corrosion. The methodology will be usable for the fatigue assessment of existing steel riveted bridge structures affected by corrosion. Moreover, various scenarios related to maintenance will be taken into account for the remaining service life calculation. 


\section{Remaining Fatigue Life Analysis}

\section{Fatigue Life Assessment Approaches}

Many damage accumulation models have been developed. ${ }^{10}$ These models may be classified into two categories: linear damage cumulative theories and nonlinear damage cumulative theories.

The linear damage accumulation theory, also known as the PalmgrenMiner rule, ${ }^{11}$ is the most commonly used approach for cumulative fatigue damage analysis. The advantage of this method is its relative simplicity.

The coefficient of fatigue damage according to the Palmgren-Miner rule can be calculated according to Eq. (1):

$$
D=\sum_{i=1}^{n} \frac{n_{i}}{N_{i}}
$$

The end of fatigue life is given by reaching $D \geq 1$.

However, there are some disadvantages of the Palmgren-Miner method in comparison to nonlinear damage cumulative theories: the PalmgrenMiner rule does not consider load history, load interaction effects are not considered and cumulative damage has no relationship with load sequence effects. For these reasons, models of nonlinear damage accumulation were developed. These models take into account load interaction effects:

\section{Corten-Dolan model ${ }^{12}$}

The criterion of failure for the CortenDolan model is given as Eq. (2):

$$
1=\sum_{i=1}^{n} \frac{n_{i}}{N_{1}\left(\sigma_{\max } / \sigma_{i}\right)^{d}}
$$

2. Morrow's plastic work interaction rule 13

The coefficient of fatigue damage under a variable-amplitude loading spectrum can be expressed as Eq. (3):

$$
D=\sum_{i}^{n} \frac{n_{i}}{N_{i}}\left(\frac{\sigma_{i}}{\sigma_{\max }}\right)^{f}
$$

\section{V. Dattoma's model ${ }^{14}$}

The coefficient of fatigue damage can be calculated according to Eq. (4):

$$
D=1-\left[1-\left(\frac{n_{i}}{N_{f}}\right)^{1 /(1-\alpha)}\right]^{1 /(1-\beta)}
$$

Besides these models, there are many other models in the category of nonlinear damage cumulative theories, ${ }^{10}$ e.g. the Freudenthal-Heller model and Carpinteri's model.

\section{Stress Spectrum Calculation}

If the effects of traffic are known, then it is possible to make a more accurate calculation of the remaining fatigue life by determining the equivalent stress range using a cycle counting method and an approach of cumulative fatigue damage. Then, the stress spectrum, which is the stress range and the associated number of cycles in descending order, needs to be determined. The input data for calculation of the stress spectrum may be obtained in the following ways:

1. Real data obtained from taking measurements on the existing structure. Permanent or temporary monitoring of bridge structures is a very important method used during the bridge diagnostics. In this case, measurement devices and sensors, e.g. strain gauges, are installed in selected locations on the structure. Relative strain dependent on time is the most common form of data obtained by this method. Bridge monitoring is applied during load tests or to obtain information about the effects of day-to-day transport. According to the length of monitoring time, the obtained data may contain effects of one or more trains that crossed over the bridge. For evaluation of the data, a sorting method can be used. The result of this method is the stress spectrum, obtained in the place where the strain gauge was located on the structure.

2. Data obtained from numerical models of the evaluated bridge. Suitable software that enables time history analysis can be used to obtain data for the stress spectrum calculation. A numerical model of the bridge is loaded by load model LM71 or models of real trains, and the effects on the behaviour of the bridge structure are observed. The result of this method is the stress range (or stress amplitude) on individual components obtained from one crossing of the load model.

\section{Stress Spectrum Generator}

A computer program called Stress Spectrum Generator was created in MATLAB $^{\circledR}$ software. This is a tool for stress spectrum calculation developed by the authors. The computation algorithm is based on the rainflow counting method. The input data have a form of stress (or strain) over time. If the input data have a form of relative strain, the values are multiplied by the modulus of elasticity and converted into stress values. The outputs from the program are stress ranges divided into a selected number of intervals and a number of cycles of stress ranges falling into the individual intervals. The mean value of each interval is the representative value of the stress range. If the input data were obtained from a static load test, the values of the stress range may be multiplied by a dynamic factor, which is computed according to the selected method.

\section{Calculation Model for Fatigue Behaviour Prediction of Corroded Steel Bridge Members}

Insufficient background and tools are available for the assessment of remaining fatigue life of corroded structures. However, the need for more precise reassessment of existing bridges is becoming more important. For this reason, the calculation model for the fatigue behaviour prediction of corroded steel structures was developed by the authors.

The calculation model, called FALCom (Fatigue Assessment on Level of Component), is a program created in MATLAB software. The model includes the Stress Spectrum Generator program, which enables stress spectra to be calculated. In addition, the results of laboratory fatigue tests on deteriorated riveted members ${ }^{7}$ are integrated into the model. The model provides the 
calculation relationships considering the change in detail category due to corrosion loss.

\section{Methodology of the Calculation Model}

The model was created to calculate the fatigue damage of structural members that are or are not deteriorated by corrosion and to estimate the remaining service life of such elements. The program is composed of several modules that are connected together: (a) corrosion effects, (b) stress spectrum calculation, (c) calculation of fatigue damage, (d) calculation of remaining fatigue life, and (e) financial costs estimation.

\section{Corrosion Effects}

The rate of corrosion loss is taken into account by corrosion models. Several corrosion models ${ }^{3}$ are included in FALCom: (a) the power model, (b) the corrosion model in Ref. [15], and (c) the corrosion model in Ref. [16]

\section{Stress Spectrum Calculation}

The program Stress Spectrum Generator is included in the calculation model (see "Stress Spectrum Calculation" in the previous section). On the basis of known traffic intensity of individual train units crossing over the bridge, the number of cycles per year is calculated. Stress spectra determined for each train unit are the results of the calculation. If necessary, the obtained values of stress range may be multiplied by dynamic factor.

\section{Calculation of Fatigue Damage}

The fatigue assessment of critical bridge components is based on the approach of cumulative fatigue damage. The following linear and nonlinear theories mentioned in "Fatigue Life Assessment Approaches" in the previous section are considered in the methodology: (a) linear cumulative damage theory-the Palmgren-Miner rule, and (b) nonlinear cumulative damage theories-Corten-Dolan's model, ${ }^{12}$ Morrow's plastic work interaction model $^{13}$ and V. Dattoma's model. ${ }^{14}$

The calculation program takes into account possible weakening of the evaluated members due to corrosion, which is considered by changes in detail category over time. The relationship for the reduction of detail category was taken from the results of laboratory tests focusing on the fatigue behaviour of corroded elements. $^{7}$

\section{Calculation of Remaining Fatigue Life}

The calculation of remaining service life is based on the computational relationships of linear and nonlinear theories mentioned above. In addition, various scenarios considering the different maintenance methods are taken into account. Scenarios for the maintenance of structural members or the whole structure are stated in Table 1.

The following values are calculated for each scenario: coefficient of fatigue damage in the future, remaining service life and total service life of the assessed member.

\section{Financial costs estimation}

The financial costs necessary to maintain the structure during the required remaining service life are estimated on the basis of various scenarios. The scenarios stated in Table 1 are considered for the calculation. Activities and subactivities related to these scenarios are introduced in Table 2. The total financial costs associated with maintenance are subsequently calculated for each scenario as the sum of costs for individual activities.

An approach taking into account the net present value (NPV) was used to compare past and future cash flows with the current ones. Costs are discounted to a common time to be time equivalent. The discount rate of money reflects the cost of the investor's missed opportunities over time. The NPV for costs, taking into account inflation, is determined according to Eq. (5):

$$
\mathrm{NPV}=\sum_{t=t_{M}}^{n} \frac{I M \cdot(1+i)^{t}}{(1+d)^{t}}
$$

\begin{tabular}{|l|l|l|}
\hline 1 & \multicolumn{1}{|c|}{ Scenario } & \multicolumn{1}{c|}{ Scenario description } \\
\hline 1 & No maintenance & $\begin{array}{l}\text { There is no maintenance of the structure and structural elements from the corrosion } \\
\text { point of view. The coating is not applied } \rightarrow \text { the corrosion process continues } \rightarrow \text { the detail } \\
\text { category gets worse } \rightarrow \text { the remaining life of structural elements is the shortest }\end{array}$ \\
\hline 2 & Coating application & $\begin{array}{l}\text { The coating is applied on the whole structure or on the critical members } \rightarrow \text { the corrosion } \\
\text { process does not continue during the coating lifetime. The detail category does not get } \\
\text { worse if: (a) the coating lifetime is longer than or equal to the required remaining life of } \\
\text { the structure, and (b) the coating is reapplied before the end of its lifetime. If the } \\
\text { effectiveness of the coating is lost and there is no reapplication, then the corrosion } \\
\text { process continues and the detail category gets worse with time. Finally, the remaining life } \\
\text { of structural elements is longer than in scenario 1 }\end{array}$ \\
\hline 3 & $\begin{array}{l}\text { Strengthening of the critical members }+ \\
\text { coating application }\end{array}$ & $\begin{array}{l}\text { Strengthening of the critical members is applied. For example, a steel sheet is welded to } \\
\text { the bottom flange of the cross-beam } \rightarrow \text { the strain of the members increases } \rightarrow \text { the stress } \\
\text { range increases. At the same time, any increase in the corrosion loss is prevented due to } \\
\text { the coating application and the impacts are the same as in scenario 2. The remaining life } \\
\text { of structural elements is longer than in scenarios 1 and 2 }\end{array}$ \\
\hline 4 & Replacement of the critical members & $\begin{array}{l}\text { The critical structural member is replaced by a new element } \rightarrow \text { the detail category is } \\
\text { equal to (or higher than) the detail category of the original uncorroded member. The } \\
\text { remaining life of the structural element is longer than in scenarios 1, 2 and } 3\end{array}$ \\
\hline
\end{tabular}

Table 1: Scenarios considered for remaining service life calculation 


\begin{tabular}{|c|c|c|}
\hline Scenario & Scenario title & $\begin{array}{c}\text { Activities related to financial costs in } \\
\text { terms of maintenance }\end{array}$ \\
\hline 1 & No maintenance & None \\
\hline \multirow[t]{3}{*}{2} & \multirow[t]{3}{*}{ Coating application } & 1. Sandblasting of corroded surface \\
\hline & & 2. Grease removal \\
\hline & & 3. Coating application \\
\hline \multirow[t]{4}{*}{3} & \multirow{4}{*}{$\begin{array}{l}\text { Strengthening of the critical } \\
\text { members + coating application }\end{array}$} & 1. Sandblasting of corroded surface \\
\hline & & 2. Grease removal \\
\hline & & 3. Strengthening application \\
\hline & & 4. Coating application \\
\hline \multirow[t]{3}{*}{4} & \multirow[t]{3}{*}{ Replacement of the critical members } & 1. Removal of the original member \\
\hline & & $\begin{array}{l}\text { 2. Mounting new steel members } \\
\text { including coating application }\end{array}$ \\
\hline & & 3. Coating application \\
\hline
\end{tabular}

Table 2: Activities related to financial costs in terms of maintenance where $I M$ is the financial costs for maintenance $(€), i$ is the inflation rate $(\%), d$ is the discount rate $(\%), t_{M}$ is the year of maintenance, and $n$ is the required remaining service life of a bridge (years).

The outputs from the FALCom program are as follows:

1. Stress spectrum calculated for all train units crossing over the bridge: number of cycles per crossing and per year.

2. Coefficient of fatigue damage in history: includes the time period from bridge construction to the assessment.

3. Coefficient of fatigue damage in the future: includes the time period fro the assessment (or since the completion of bridge reconstruction) to the expiration of required remaining life.

4. Remaining service life (years).

5. Total service life (years).

6. Financial costs for the owner necessary to maintain the structure during the required remaining service life.

Points 3-6 are calculated for various scenarios, which depend on the maintenance method or on the type of reconstruction.

\section{Comparison of Results of the Calculation Model and Laboratory Fatigue Tests}

As mentioned in the subsection "Combination of Fatigue and Corrosion
The reduced detail category was calculated on the basis of the original detail category, level of corrosion weakening and cross-sectional dimensions of tested samples.

The mean value of the reduced detail category can be calculated according to Eqs. (6) and (7):

$$
\begin{aligned}
& \Delta \sigma_{c, R, 50}=\Delta \sigma_{c} \cdot c_{R, 50} \quad[\mathrm{MPa}] \\
& c_{R, 50}=\left(1-0.4874 \cdot d_{A}\right) \quad[-]
\end{aligned}
$$

The $95 \%$ quintile value of the reduced detail category can be according to Eqs. (8) and (9):

$$
\begin{gathered}
\Delta \sigma_{c, R, 95}=\Delta \sigma_{c} \cdot c_{R, 95} \quad[M P a] \\
c_{R, 95}=\left(1-0.9954 \cdot d_{A}\right)
\end{gathered}
$$

where $\Delta \sigma_{c}$ is the original detail category of an uncorroded sample, $c_{R, 50}$ and $c_{R, 95}$ are reduction coefficients, and $d_{A}$ is the level of corrosion determined as the change in cross-sectional area.

The original detail category of the tested riveted connection was 71 . Considering the values of stress ranges obtained from fatigue tests, the number of cycles until failure was calculated (Table 3 and Fig. 1). The calculated number of cycles for the $95 \%$

\begin{tabular}{|l|c|c|c|c|c|c|}
\hline \multirow{2}{*}{} & \multicolumn{5}{|c|}{ Number of cycles } \\
\cline { 2 - 7 } & & Experiment & $\begin{array}{c}\text { Calculated } \\
\text { (mean) }\end{array}$ & $\begin{array}{c}\boldsymbol{N}_{\text {exp }} / \boldsymbol{N}_{\text {calc, }} \\
\text { mean }\end{array}$ & $\begin{array}{c}\text { Calculated (95\% } \\
\text { quintile) }\end{array}$ & $\begin{array}{c}\boldsymbol{N}_{\text {exp }} / \boldsymbol{N}_{\text {calc, }} \\
\mathbf{9 5 \%} \mathbf{q}\end{array}$ \\
\cline { 2 - 7 } Sample & $\boldsymbol{N}_{\text {exp }}$ & $\boldsymbol{N}_{\text {calc, mean }}$ & $\Delta \boldsymbol{N}$ (\%) & $\boldsymbol{N}_{\text {calc, 95\% q }}$ & $\Delta \mathbf{N}$ (\%) \\
\hline 1 & S1.1 & 184452 & 194455 & -5 & 95228 & 94 \\
\hline 2 & S1.2 & 251053 & 227343 & 10 & 111333 & 125 \\
\hline 3 & S1.3 & 186320 & 213522 & -13 & 104565 & 78 \\
\hline 4 & S1.4 & 300140 & 314553 & -5 & 154042 & 95 \\
\hline 5 & S2.1 & 179633 & 202261 & -11 & 99051 & 81 \\
\hline 6 & S2.2 & 161769 & 131912 & 23 & 64600 & 150 \\
\hline 7 & S2.3 & 222551 & 218639 & 2 & 107071 & 108 \\
\hline 8 & S3.1 & 139313 & 201414 & -31 & 98636 & 41 \\
\hline 9 & S3.2 & 62003 & 57016 & 9 & 27922 & 122 \\
\hline 10 & S3.3 & 182980 & 139719 & 31 & 68422 & 167 \\
\hline 11 & S4.1 & 104000 & 209654 & -50 & 102671 & 1 \\
\hline 12 & S4.2 & 171843 & 198642 & -13 & 97278 & 77 \\
\hline 13 & S4.3 & 313553 & 259664 & 21 & 127162 & 147 \\
\hline
\end{tabular}

Table 3: Comparison of the results of the calculation model and laboratory fatigue tests 


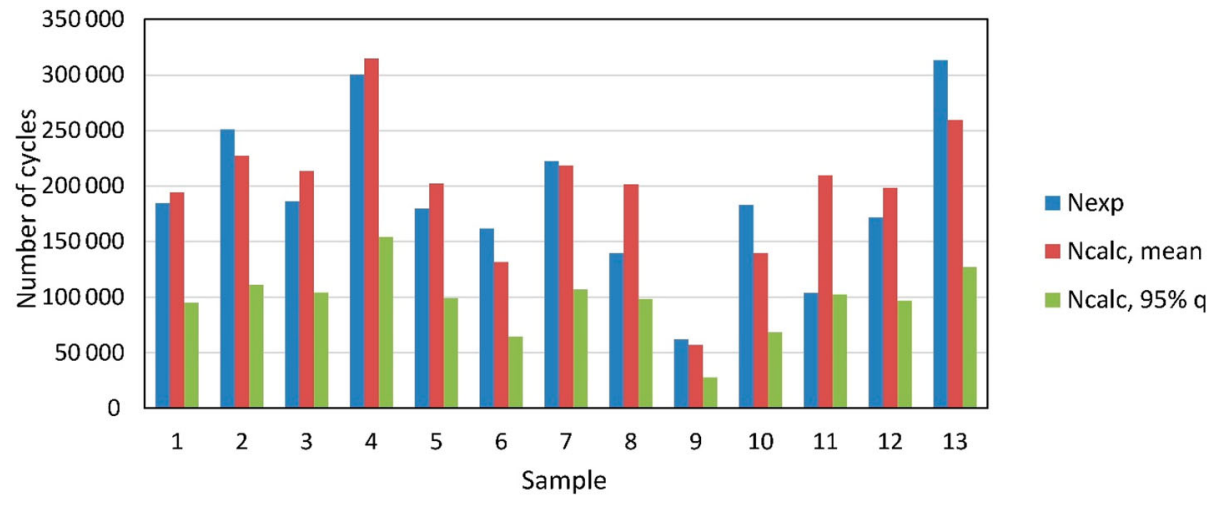

Fig. 1: Comparison of the results of the calculation model and laboratory fatigue tests. Nexp $=$ experimental; Ncalc $=$ calculated $; 95 \% q=95 \%$ quintile

quantile was lower in all cases in comparison with the measured numbers, which means that the calculation is on the safe side.

\section{Case Study}

The application of the method described in the previous section for the assessment of the remaining fatigue life of components is shown in a practical example. The most critical components with respect to fatigue of an old railway steel bridge were assessed and the possibilities for extending the service life of the bridge were analysed.

\section{Description of the Bridge}

An existing steel railway bridge is used to present the methodology in practice (Fig. 2). The bridge is situated in the Hlubočepské valley in Prague, Czech Republic, and takes a single-track railway over Dalejský brook. The angle of crossing is 70 degrees. The track on the bridge is located in a right-hand arc with a diameter of $334.0 \mathrm{~m}$. The span is $10.0 \mathrm{~m}$, the width is $5.65 \mathrm{~m}$ and the total length of the bridge is $26.70 \mathrm{~m}$. From the static point of view, the bridge acts as a simply supported beam. The design velocity of track is $70 \mathrm{~km} / \mathrm{h}$. The bridge was built in 1872 .

The load-bearing structure consists of two main riveted steel girders of length $10.60 \mathrm{~m}$ and the axial distance between them is $2.16 \mathrm{~m}$. The height of the girders is not constant, but changes along the length; this is caused by the varying thickness of the upper and bottom flanges: the outside parts are $890 \mathrm{~mm}$, the intervening parts are $900 \mathrm{~mm}$ and the middle parts are $918 \mathrm{~mm}$ thick. The upper flange is composed of two to four steel sheets of

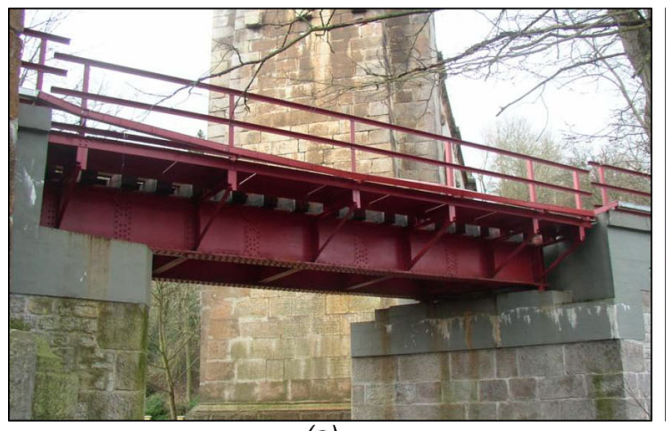

(a)
Fig. 3: Bridge load: history and future prediction axial distance of the bracing is from 1.99 to $2.15 \mathrm{~m}$. The length of crossbeams is $2.16 \mathrm{~m}$, which is the same value as the axial distance of the main girders. The longitudinal bracing of the bridge is composed of bars with cross-section of angles $L 70 \times 70 \times 8$. These bars, with length $3.0 \mathrm{~m}$, create a truss structure and each pair of crossing members is joined with one rivet. This bracing is connected to the upper bars of the lateral bracing and to the upper flanges of the main girders.

\section{Current State of the Bridge}

A detailed inspection of the bridge has been carried out and the following damage has been discovered. The upper flanges of the main girders have been weakened by corrosion pits and the measured difference between the original and current thickness is $5-6 \mathrm{~mm}$ in some parts. The average value of corrosion loss is about $3 \mathrm{~mm}$. Some of the rivets have also been affected by corrosion and the material loss of rivet heads is $30-40 \%$ in some cases. The corrosion weakening of the bottom flanges is located close to the support owing to the presence of soil, dust and vegetation. The flange angle is the member most affected by corrosion. The average corrosion loss on

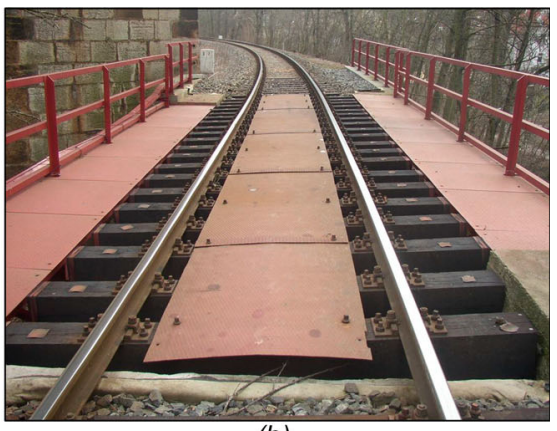

(b)

Fig. 2: Railway bridge: (a) longitudinal view; (b) view of the superstructure

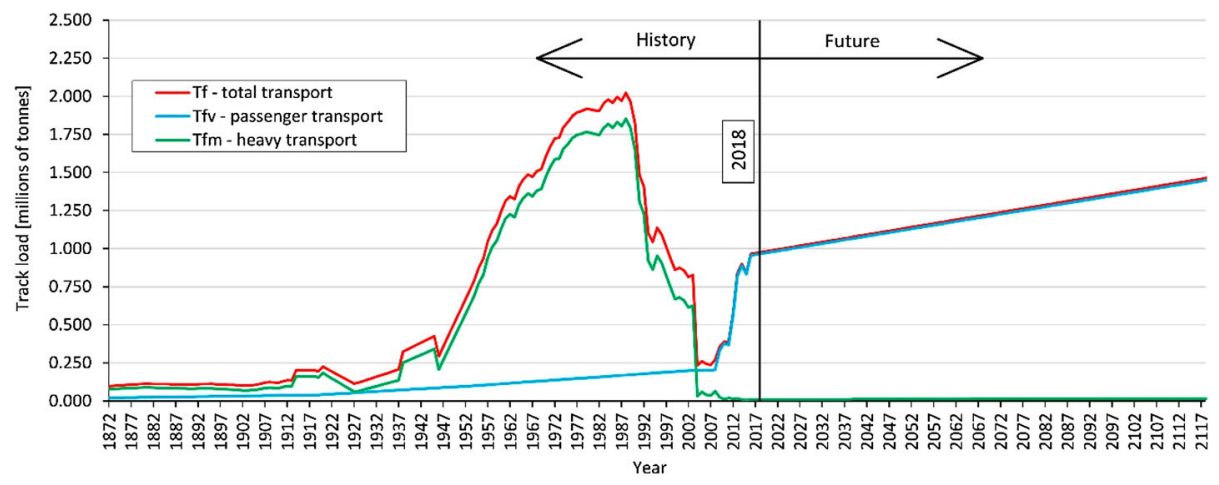


the flange angle is about $4 \mathrm{~mm}$, especially on the upper surface of the horizontal flange. This fact may have a big influence on the load-bearing capacity and fatigue behaviour of damaged elements and also of the whole structure.

The members of the transverse and longitudinal bracing have not been affected by corrosion or mechanical damage.

The steel structure is made of mild steel with material properties according to Ref. [1]:

- modulus of elasticity: $E=$ $200000 \mathrm{MPa}$

- yield strength: $f_{y}=210 \mathrm{MPa}$

- ultimate strength: $f_{u}=340 \mathrm{MPa}$.

\section{Fatigue Load and Corrosion Exposure}

For the fatigue assessment, only the effects of traffic load, which belongs to the group of variable loads, were considered. Other effects of variable loads, such as wind load, snow load and temperature effects, were neglected.

The load development over time on the track, where the bridge is situated, was taken according to Refs. [17,18]. Figure 3 shows how passenger and heavy transport changed during the service life of the bridge. It can be seen that there have been big load fluctuations in the bridge's history. At the beginning of the bridge's operation, in 1872 , the value of the total load was 0.1 million tonnes per year. This was followed by a gradual increase in passenger and heavy traffic. The most significant changes occurred in the period after the Second World War and the maximum value of track load (2 million tonnes per year) was reached in 1988. Since then, the value of heavy transport started to decrease rapidly (until 2004), although passenger transport continued to increase.

The year 2018 is considered as the year of the assessment, when the value of total track load was 0.98 million tonnes per year. In contrast to the historical loads, at present the passenger transport represents a greater portion of the total load than the heavy transport.

In the future, a slight increase in traffic load may be expected. For this reason, the development of traffic load on the

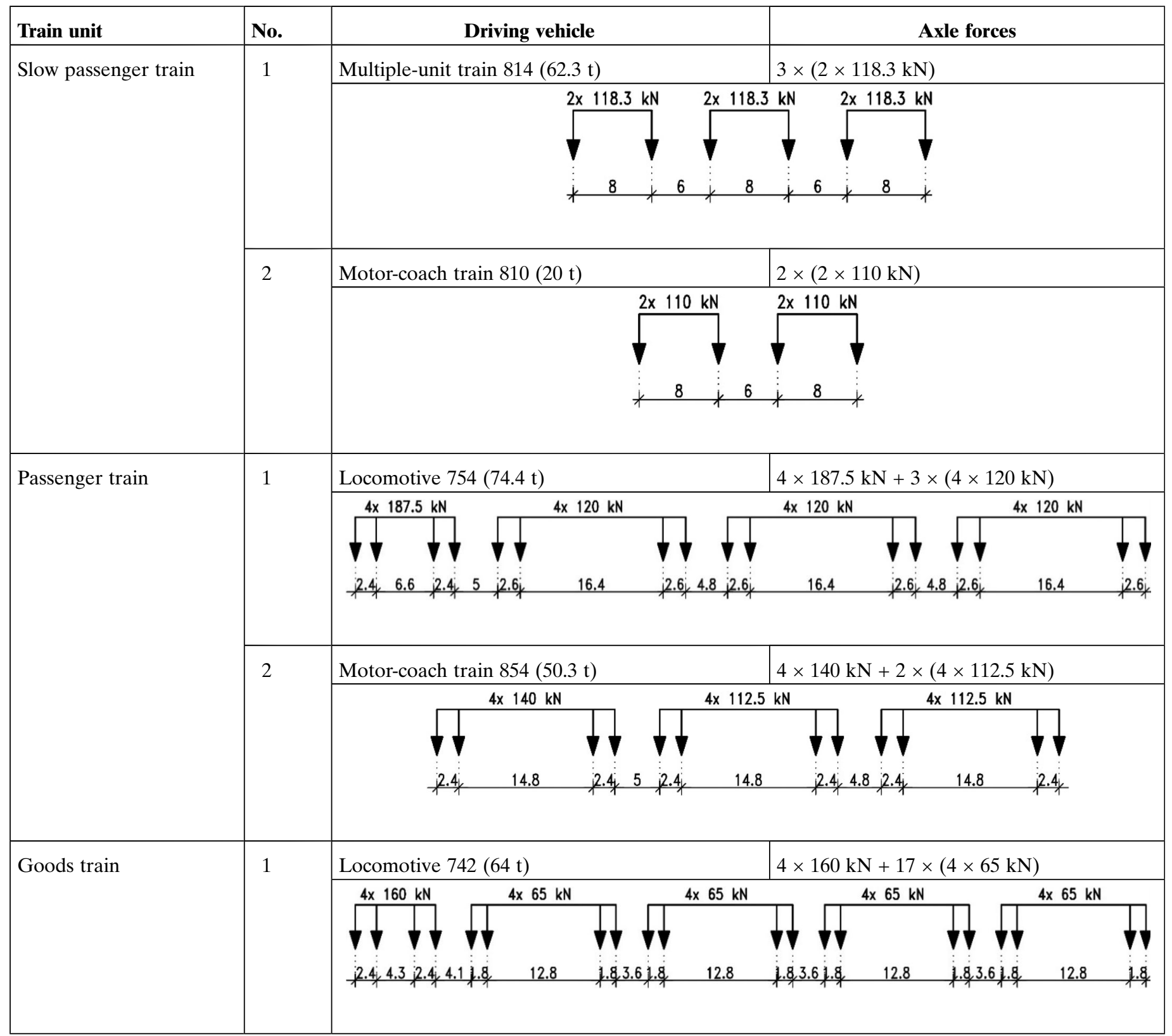




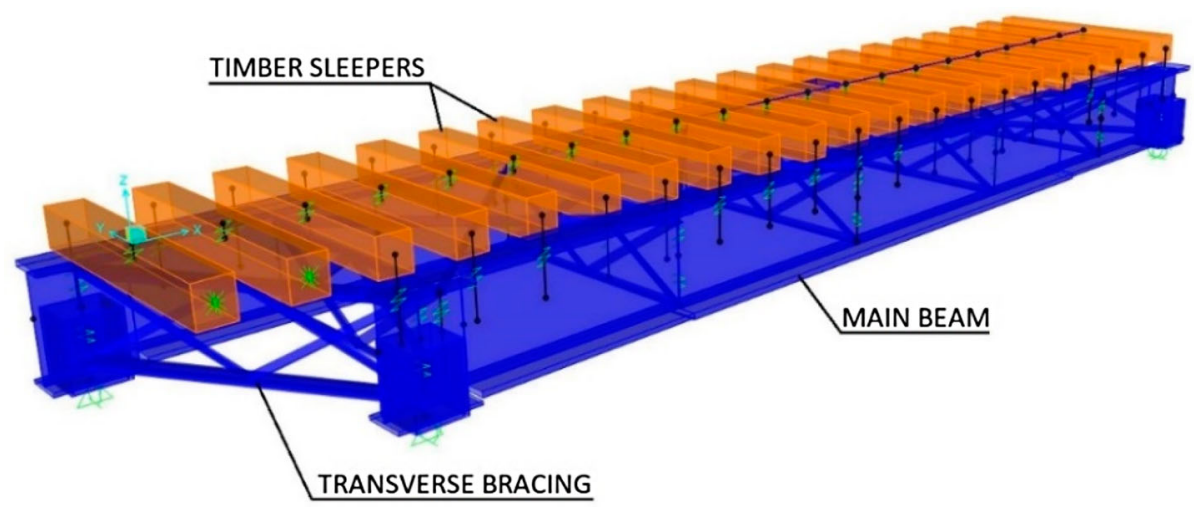

Fig. 4: Numerical model of the bridge

bridge in the future is predicted as follows: the load caused by passenger and heavy transport will increase by $0.5 \%$ per year (Fig. 3). These data are used for the remaining service life calculation.

The number of trains crossing the bridge during one day in 2018 was found out according to the train timetable:

- slow passenger trains: 13

- passenger trains: 58

- goods trains: 2 .

Five train units were chosen to represent the movable load on the bridge. Two of them belong to "slow passenger trains", where any axle force is not higher than $120 \mathrm{kN}$. Another two train units with axle forces higher than $120 \mathrm{kN}$ for each driving vehicle fall into "passenger trains". The last one of the train units is a goods train, which consists of one locomotive and 17 railway cars with a total weight of $5060 \mathrm{t}$. An overview of train units crossing over the bridge at present is presented in Table 4.

As described in "Description of the Bridge" (above), the main beams are affected by corrosion, especially due to the negative impacts of weather. The average value of corrosion loss on the upper and the bottom flanges is 3 and $4 \mathrm{~mm}$, respectively. This fact is taken into account in the assessment of the remaining fatigue life of bridge components. Corrosion models are used for the calculation of corrosion rates in the past and for the prediction of corrosion rates in the future. The assumption is that the coating was applied only during the bridge construction and not reapplied later, up to the present. The coating was estimated to be effective for 20 years.

\section{Numerical Model}

A three-dimensional numerical model of the bridge was created in CSI Bridge software $t$ determination of the stress ranges that were used for (a)
(1) NO MAINTENANCE

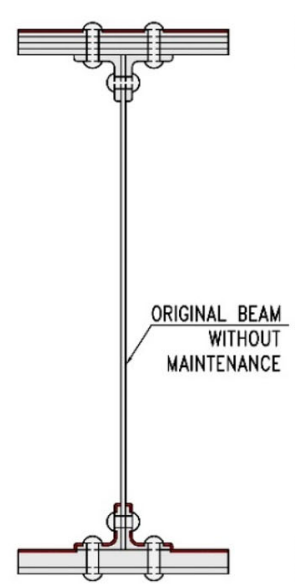

(2) COATING APPLICATION

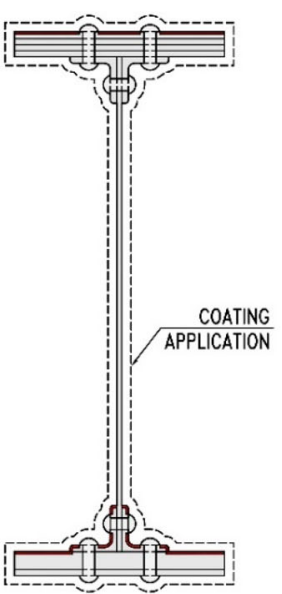

Fig. 6: Maintenance scenarios fatigue assessment. All bridge components were modelled as bar elements (one dimension) with the real cross-section characteristics (Fig. 4). Three different cross-sections of main girders due to various thickness of flanges (see "Description of the Bridge", above) were taken into account in the model. Transverse bracing was composed of two isosceles angles $L 80 \times 80 \times 10$ in the upper plane and two isosceles angles $L 80 \times 80 \times 10$ in the bottom plane. Four crossed diagonals with cross-section $L 70 \times 70 \times 8$ filled in the space between the upper and bottom angles. Connections of $2 L 80 \times 80 \times 10$ to the main girders were modelled by articulated joints in the horizontal and vertical directions as well as the connection of bars $L 70 \times 70 \times 8$ with $2 L 80 \times 80 \times 10$. Connections of crossed diagonals were

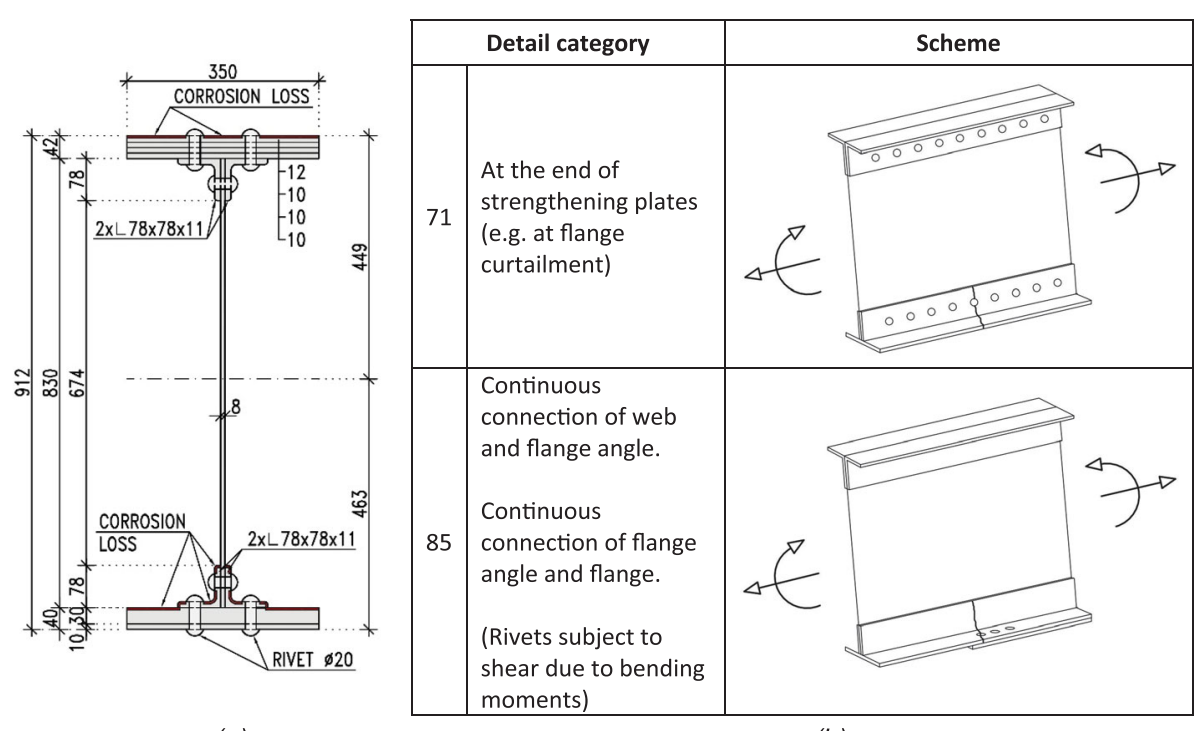

(b)

Fig. 5: (a) Beam cross-section; (b) evaluated detail category

(3) STRENGTHENING + COATING APPLICATION

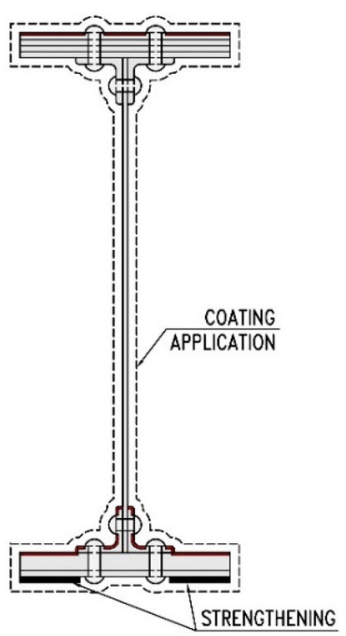

(4) REPLACEMENT

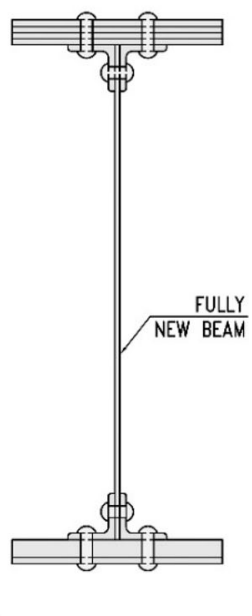


modelled by articulated crossing to ensure the interaction between them. Horizontal bracing was modelled using bar elements with cross-section of angles $L 70 \times 70 \times 8$. Bars were connected to the main girders by solid bonds; however, joints, which allow rotation in both vertical and horizontal directions, were placed on both ends of the bracing. Fixed bearings of the bridge, which are located closer to Prague-Smíchov station, were modelled as flexible in the longitudinal and transversal directions of the bridge. One-direction movable bearings, which are situated closer to Rudná station, were modelled as flexible in the transversal direction of the bridge.

Train units that are currently crossing over the bridge were modelled as a movable load. Axle forces and distances between them fully corresponded to diagrams stated in Table 4. The crossing time of each train unit was set up on the basis of the total train length and the speed of $70 \mathrm{~km} / \mathrm{h}$, which is the maximum allowed speed of trains on the bridge. The value of modal damping was set to 0.01 .

The movable load was located on a track whose position was the same as the position of railway track axis. The track was modelled as a curved bar with radius $R=334 \mathrm{~m}$ and was situated $47 \mathrm{~mm}$ above the sleepers. The track was joined with the sleepers using solid bonds. Cross-sectional characteristics of the bar were the same as the characteristics of two rails S49.

\begin{tabular}{|c|c|c|c|c|c|}
\hline \multirow{3}{*}{$\begin{array}{l}\text { Scenario } \\
1 \\
\end{array}$} & \multirow{3}{*}{\begin{tabular}{|l}
\multicolumn{1}{c}{ Scenario title } \\
No maintenance \\
\end{tabular}} & \multicolumn{4}{|c|}{ Activities and financial costs related to maintenance } \\
\hline & & \multirow{2}{*}{ Activity } & \multicolumn{2}{|l|}{ Costs } & \multirow{2}{*}{$\begin{array}{c}\text { Unit } \\
(€) \\
\end{array}$} \\
\hline & & & - & 0 & \\
\hline \multirow[t]{8}{*}{2} & \multirow[t]{8}{*}{ Coating application } & \multirow[t]{2}{*}{ 1. Sandblasting of corroded surface } & Costs & 4 & $\left(€ / \mathrm{m}^{2}\right)$ \\
\hline & & & Area & 65 & $\left(\mathrm{~m}^{2}\right)$ \\
\hline & & \multirow[t]{2}{*}{ 2. Grease removal } & Costs & 1 & $\left(€ / \mathrm{m}^{2}\right)$ \\
\hline & & & Area & 65 & $\left(\mathrm{~m}^{2}\right)$ \\
\hline & & \multirow[t]{3}{*}{ 3. Coating application } & Costs & 40 & $\left(€ / \mathrm{m}^{2} /\right.$ layer $)$ \\
\hline & & & Area & 65 & $\left(\mathrm{~m}^{2}\right)$ \\
\hline & & & Number of coatings & 3 & (coatings) \\
\hline & & \multicolumn{2}{|l|}{ 4. Additional costs } & 0 & $(€)$ \\
\hline \multirow[t]{10}{*}{3} & \multirow{10}{*}{$\begin{array}{l}\text { Strengthening of the critical members + } \\
\text { coating application }\end{array}$} & \multirow[t]{2}{*}{ 1. Sandblasting of corroded surface } & Costs & 4 & $\left(€ / \mathrm{m}^{2}\right)$ \\
\hline & & & Area & 65 & $\left(\mathrm{~m}^{2}\right)$ \\
\hline & & \multirow[t]{2}{*}{ 2. Grease removal } & Costs & 1 & $\left(€ / \mathrm{m}^{2}\right)$ \\
\hline & & & Area & 65 & $\left(\mathrm{~m}^{2}\right)$ \\
\hline & & \multirow[t]{2}{*}{ 3. Strengthening application } & Costs & 8 & $(€ / \mathrm{kg})$ \\
\hline & & & Weight & 161 & $(\mathrm{~kg})$ \\
\hline & & \multirow[t]{3}{*}{ 4. Coating application } & Costs & 40 & $\left(€ / \mathrm{m}^{2} /\right.$ layer $)$ \\
\hline & & & Area & 65 & $\left(\mathrm{~m}^{2}\right)$ \\
\hline & & & Number of coatings & 3 & (coatings) \\
\hline & & \multicolumn{2}{|l|}{ 5. Additional costs } & 0 & $(€)$ \\
\hline \multirow[t]{10}{*}{4} & \multirow[t]{10}{*}{ Replacement of the critical members } & \multirow[t]{2}{*}{ 1. Removal of the original member } & Costs & 0.5 & $(€ / \mathrm{kg})$ \\
\hline & & & Weight & 8968 & $(\mathrm{~kg})$ \\
\hline & & \multirow{2}{*}{$\begin{array}{l}\text { 2. New steel members including } \\
\text { coating application }\end{array}$} & Costs & 6 & $(€ / \mathrm{kg})$ \\
\hline & & & Weight & 8968 & $(\mathrm{~kg})$ \\
\hline & & \multirow[t]{2}{*}{ 3. Traffic closure } & Costs & 200 & $(€ / \mathrm{h})$ \\
\hline & & & Time & 72 & (h) \\
\hline & & \multirow[t]{3}{*}{ 4. Coating application } & Costs & 40 & $\left(€ / \mathrm{m}^{2} /\right.$ layer $)$ \\
\hline & & & Area & 65 & $\left(\mathrm{~m}^{2}\right)$ \\
\hline & & & Number of coatings & 3 & (coatings) \\
\hline & & \multicolumn{2}{|l|}{ 5. Additional costs } & 0 & $(€)$ \\
\hline
\end{tabular}

Table 5: Inputs for calculation of financial costs 


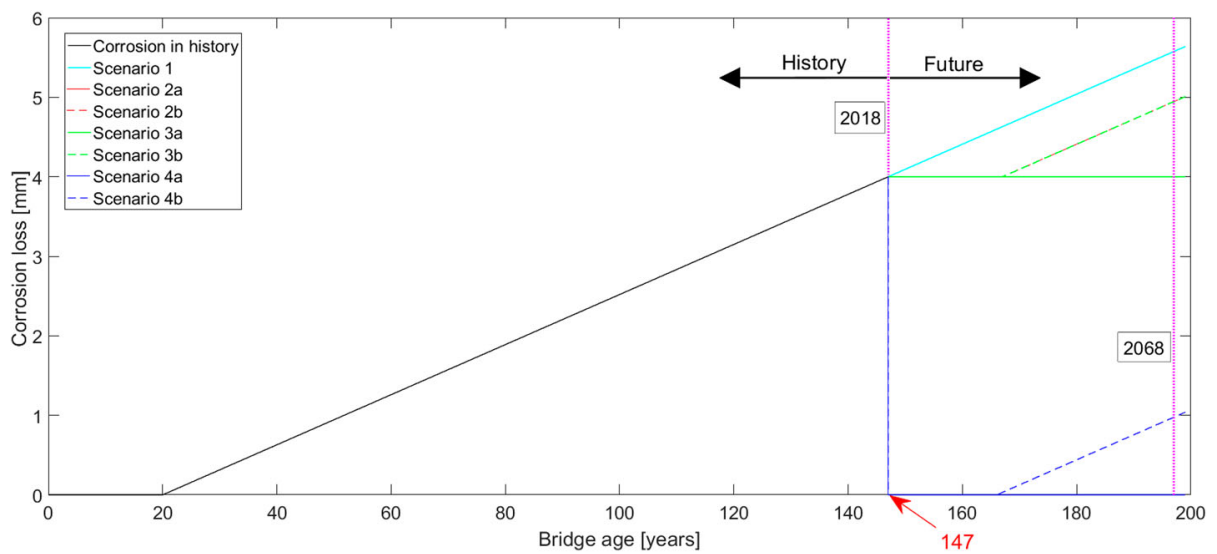

Fig. 7: Change of corrosion loss over time on the bottom flange

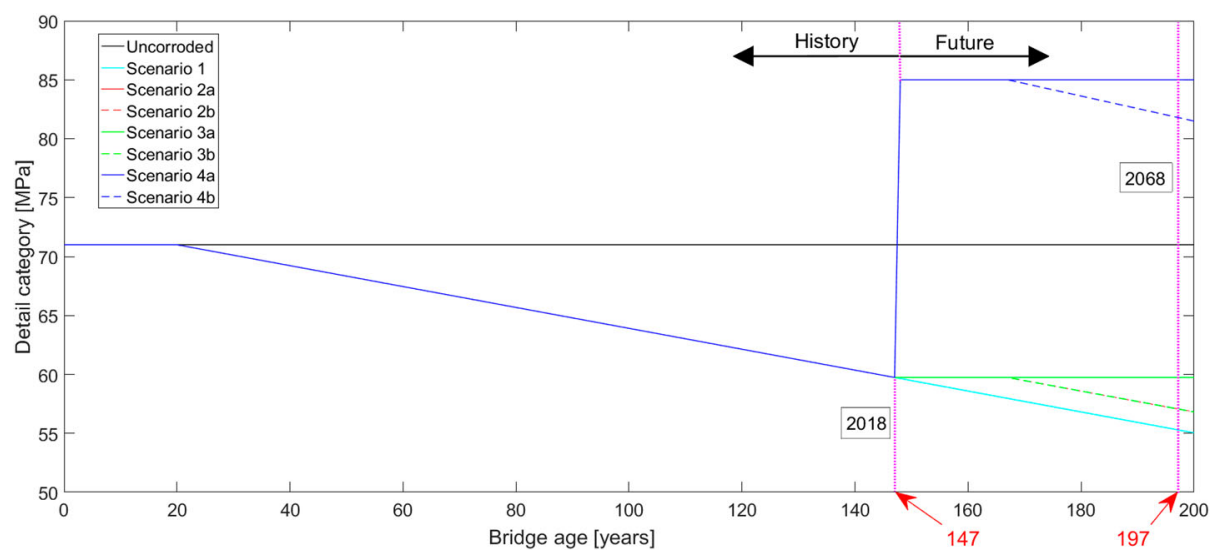

Fig. 8: Change of detail category over time

Time history analysis was applied to calculate the dependence of stress on time in the evaluated elements and cross-sections. Then, the stress spectrum caused by one crossing of a train unit was calculated using the Stress Spectrum Generator. The same procedure was applied to all models of train units. In the next step, the stress spectra for years in history were calculated on basis of the ratio of track load in 2018 to individual years in history.

\section{Members Under Assessment}

The main beams of the bridge were selected for fatigue assessment and evaluation of remaining fatigue life, for several reasons: (a) low detail category of connections according to Ref. [1], (b) high value of stress range caused by the effects of real trains, and (c) high level of corrosion weakening, especially on the upper and bottom flanges (Fig. 5).

Detail categories occurred on the main beam:
1. Detail category 71: in the place where the number of sheets, which create the bottom flange, changes. In the present case, the bottom flange in part P3 consists of two sheets (thickness: $30+10 \mathrm{~mm}$ ) and part P2 consists of one sheet (thickness: $30 \mathrm{~mm}$ ); the cross-section including the last row of rivets in part $\mathrm{P} 2$ before the change in the number of sheets was assessed.

2. Detail category 85: continuous connection of flange angle and flange; the detail was assessed in the place of maximum bending moment caused by models of real trains.

The value for the partial factor for fatigue strength is taken as: $\gamma_{M f}=1.15$.

\section{Scenarios}

For the assessment of future service life, four scenarios related to maintenance were considered (Fig. 6):

- Scenario 1: "No maintenance". There is no maintenance of the beams $\rightarrow$ the corrosion process continues and the category detail is getting worse over time. There are no costs for the owner.

- Scenario 2: "Coating application". The coating of the beams is renovated several times in a row (scenario $2 a$ ) or once (scenario $2 b$ ) according to the required remaining service life of the bridge. The corrosion process does not continue and the category detail is not getting worse.

- Scenario 3: "Strengthening of the critical members and coating application". Additional steel plates are put on the bottom flange of riveted beam for the purpose of increasing the cross-sectional area. The coating is applied several times in a row (scenario 3a) or once (scenario $3 b)$. The corrosion process does not continue, the category detail is not getting worse and the values of stress ranges are lower because of the strengthening.

- Scenario 4: "Replacement of the critical members". The original corroded beams are replaced by new elements. The coating of new beams is applied several times in a row (scenario 4a) or once (scenario 4b).

It is assumed that all of these scenarios are applied in the same year as the bridge assessment is carried out, i.e. in 2018.

Table 5 contains the inputs for the calculation of the financial costs for each scenario. Corresponding activities and costs are entered in the table according to the type of maintenance. There are zero costs for the bridge owner in terms of maintenance in case of scenario 1 , which simulates no maintenance during the future service life of the bridge. Scenarios 2 and 3 include activities related to coating application and strengthening of the critical members. Financial costs are dependent on the surface area of both main beams, the number of coatings and the weight of additional steel plates in scenario 3. Among other things, the costs of scenario 4, which is focused on replacement of the critical members, take into account the costs related to traffic closure, which is necessary during the time of reconstruction.

\section{Results and Evaluation of the Assessment}

Applying the methodology developed in the MATLAB software, the assessment of the remaining fatigue life of 


\begin{tabular}{|c|c|c|c|c|c|c|c|c|c|c|c|}
\hline \multirow{2}{*}{\multicolumn{3}{|c|}{ Palmgren-Miner }} & \multicolumn{7}{|c|}{ Scenario } & \multirow{3}{*}{\begin{tabular}{|c|} 
No corrosion \\
0.0 \\
\end{tabular}} & \multirow{3}{*}{\begin{tabular}{|l|} 
Year \\
1872 \\
\end{tabular}} \\
\hline & & & \multirow{2}{*}{\begin{tabular}{|c|}
$\mathbf{1}$ \\
0.0 \\
\end{tabular}} & \multirow{2}{*}{$\begin{array}{c}\mathbf{2 a} \\
0.0 \\
\end{array}$} & \multirow{2}{*}{\begin{tabular}{|c|}
$\mathbf{2 b}$ \\
0.0 \\
\end{tabular}} & \multirow{2}{*}{\begin{tabular}{|c|}
$\mathbf{3 a}$ \\
0.0 \\
\end{tabular}} & \multirow{2}{*}{\begin{tabular}{|c|}
$\mathbf{3 b}$ \\
0.0 \\
\end{tabular}} & \multirow{2}{*}{$\begin{array}{r}\mathbf{4 a} \\
0.0 \\
\end{array}$} & \multirow{2}{*}{$\begin{array}{c}\mathbf{4 b} \\
0.0 \\
\end{array}$} & & \\
\hline CFD & At time of bridge construction & $(-)$ & & & & & & & & & \\
\hline & At time of assessment & $(-)$ & 0.49 & 0.49 & 0.49 & 0.49 & 0.49 & 0.49 & 0.49 & 0.32 & 2018 \\
\hline & At end of required service life & $(-)$ & 0.69 & 0.66 & 0.68 & 0.58 & 0.60 & 0.03 & 0.03 & 0.39 & 2068 \\
\hline \multirow[t]{3}{*}{ Service life } & Required remaining service life & (years) & \multicolumn{8}{|c|}{50} & - \\
\hline & Calculated remaining service life & (years) & 102 & 151 & 112 & 182 & 135 & $>300$ & $>300$ & $>300$ & - \\
\hline & Total service life & (years) & 249 & 298 & 259 & 329 & 282 & $>500$ & $>500$ & $>500$ & - \\
\hline \multirow{2}{*}{\multicolumn{3}{|c|}{ Corten-Dolan }} & \multicolumn{7}{|c|}{ Scenario } & & \\
\hline & & & $\mathbf{1}$ & 2a & 2b & 3a & $\mathbf{3 b}$ & 4a & $4 \mathbf{b}$ & No corrosion & Year \\
\hline \multirow[t]{3}{*}{ CFD } & At time of bridge construction & $(-)$ & 0.0 & 0.0 & 0.0 & 0.0 & 0.0 & 0.0 & 0.0 & 0.0 & 1872 \\
\hline & At time of assessment & $(-)$ & 0.44 & 0.44 & 0.44 & 0.44 & 0.44 & 0.44 & 0.44 & 0.29 & 2017 \\
\hline & At end of required service life & $(-)$ & 0.64 & 0.61 & 0.62 & 0.53 & 0.55 & 0.02 & 0.02 & 0.36 & 2067 \\
\hline \multirow[t]{3}{*}{ Service life } & Required remaining service life & (years) & \multicolumn{8}{|c|}{50} & - \\
\hline & Calculated remaining service life & (years) & 109 & 162 & 120 & 197 & 146 & $>300$ & $>300$ & $>300$ & - \\
\hline & Total service life & (years) & 256 & 309 & 267 & 344 & 293 & $>500$ & $>500$ & $>500$ & - \\
\hline \multirow{2}{*}{\multicolumn{3}{|c|}{ Morrow }} & \multicolumn{7}{|c|}{ Scenario } & & \\
\hline & & & 1 & $2 \mathbf{a}$ & 2b & 3a & 3b & $4 a$ & $4 \mathbf{b}$ & No corrosion & Year \\
\hline \multirow[t]{3}{*}{ CFD } & At time of bridge construction & $(-)$ & 0.0 & 0.0 & 0.0 & 0.0 & 0.0 & 0.0 & 0.0 & 0.0 & 1872 \\
\hline & At time of assessment & $(-)$ & 0.43 & 0.43 & 0.43 & 0.43 & 0.43 & 0.43 & 0.43 & 0.29 & 2017 \\
\hline & At end of required service life & $(-)$ & 0.64 & 0.60 & 0.61 & 0.53 & 0.55 & 0.01 & 0.02 & 0.36 & 2067 \\
\hline \multirow[t]{3}{*}{ Service life } & Required remaining service life & (years) & \multicolumn{8}{|c|}{50} & - \\
\hline & Calculated remaining service life & (years) & 110 & 163 & 121 & 199 & 147 & $>300$ & $>300$ & $>300$ & - \\
\hline & Total service life & (years) & 257 & 310 & 268 & 346 & 294 & $>500$ & $>500$ & $>500$ & - \\
\hline \multirow{2}{*}{\multicolumn{3}{|c|}{\begin{tabular}{|l|} 
V. Dattoma \\
\end{tabular}}} & \multicolumn{7}{|c|}{ Scenario } & & \\
\hline & & & 1 & 2a & $2 \mathbf{b}$ & 3a & $\mathbf{3 b}$ & $4 \mathbf{a}$ & $4 \mathbf{b}$ & No corrosion & Year \\
\hline \multirow[t]{3}{*}{ CFD } & At time of bridge construction & $(-)$ & 0.0 & 0.0 & 0.0 & 0.0 & 0.0 & 0.0 & 0.0 & 0.0 & 1872 \\
\hline & At time of assessment & $(-)$ & 0.42 & 0.42 & 0.42 & 0.42 & 0.42 & 0.42 & 0.42 & 0.28 & 2017 \\
\hline & At end of required service life & $(-)$ & 0.62 & 0.59 & 0.60 & 0.51 & 0.53 & 0.01 & 0.01 & 0.35 & 2067 \\
\hline \multirow[t]{3}{*}{ Service life } & Required remaining service life & (years) & & & & & 50 & & & & - \\
\hline & Calculated remaining service life & (years) & 112 & 167 & 124 & 204 & 151 & $>300$ & $>300$ & $>300$ & - \\
\hline & Total service life & (years) & 259 & 314 & 271 & 351 & 298 & $>500$ & $>500$ & $>500$ & - \\
\hline
\end{tabular}

$\mathrm{CFD}=$ coefficient of fatigue damage .

Table 6: Coefficients of fatigue damage for all scenarios

the steel riveted bridge was conducted. The most critical components with respect to fatigue and corrosion loss were assessed and the possibilities for extending the service life of the bridge were analysed. On the basis of the calculations, the detail category 71 was the decisive detail from the point of view of length of remaining fatigue life. For this reason, the results are shown for the assessment of this detail.
Corrosion loss is one of the parameters that affect the length of fatigue life. Corrosion models were used to calculate corrosion rates on the bridge in history and in the future. Figure 7 shows the dependence of corrosion loss of the bottom flange on bridge age. The dependence was determined by Klinesmith's linear corrosion model. ${ }^{3}$ The effectiveness of the original protective coating was estimated at 20 years. After the effectiveness of the coating was lost, the corrosion weakening began. At the time of bridge assessment, the average corrosion loss value was equal to $4 \mathrm{~mm}$, which corresponds to the measured value. Regarding the corrosion loss in the future, scenario 1 leads to the highest value. Each of scenarios 2, 3 and 4 is divided into two cases: the full lines correspond to the situation 
when the coating is applied repeatedly, which means that the corrosion loss is no longer increasing. On the other hand, the dashed lines symbolize only one application of coating with an effectiveness of 20 years. The red and green lines in scenarios 2 and 3 overlap because of the similar maintenance procedure. The bridge age at the time of evaluation was 147 years.

The presence of corrosion loss has a negative impact on the fatigue behaviour of the corroded elements. The main reason for the is the changing of detail category with various corrosion levels. ${ }^{7}$ The change in detail category over time is shown in Fig. 8. The original detail category of the evaluated member was assumed to be 71 . In scenario 1 , which corresponds to no bridge maintenance, the detail category is getting worse during the whole future service life of the bridge, because the process of corrosion loss is not stopped or interrupted. Scenarios 2 and 3 have a similar effect: the detail category is not getting worse during the time of coating effectiveness. Finally, the

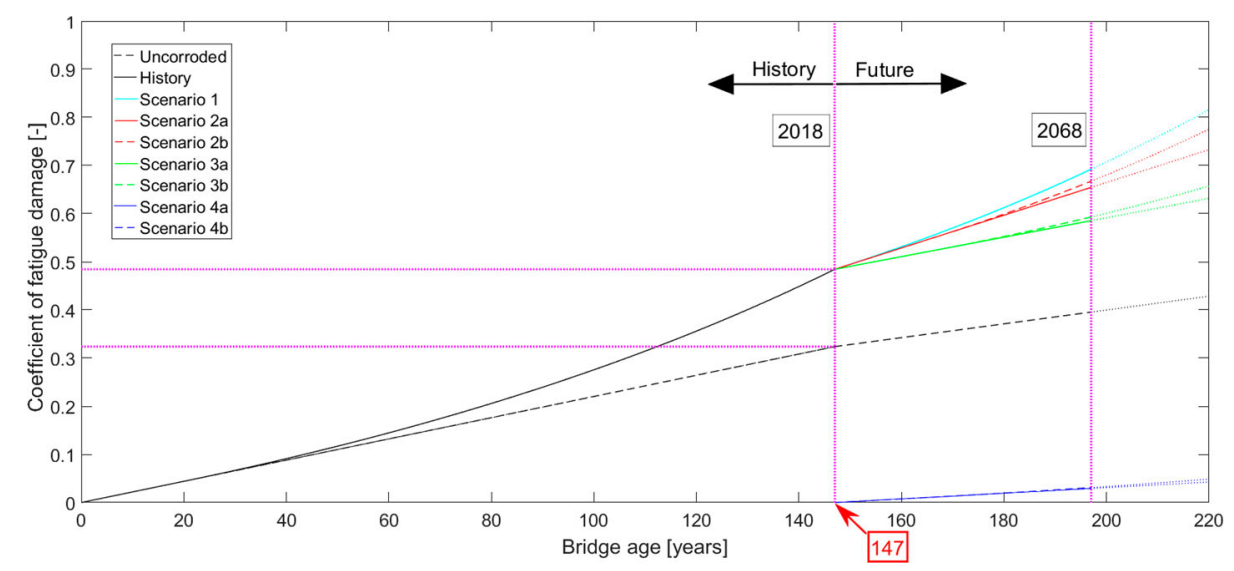

Fig. 9: Dependence of fatigue damage coefficients on time (Palmgren-Miner linear theory)

\begin{tabular}{|l|r|}
\hline \multirow{2}{*}{ Scenario } & \multicolumn{1}{|c|}{ Costs } \\
\cline { 2 - 2 } [EURO] \\
\hline Scenario 1 & 0 \\
\hline $\begin{array}{l}\text { Scenario } \\
2 \mathrm{a}\end{array}$ & 68000 \\
\hline $\begin{array}{l}\text { Scenario } \\
\text { 2b }\end{array}$ & 22000 \\
\hline $\begin{array}{l}\text { Scenario } \\
\text { 3a }\end{array}$ & 77000 \\
\hline $\begin{array}{l}\text { Scenario } \\
\text { 4b }\end{array}$ & 30000 \\
\hline $\begin{array}{l}\text { Scenario } \\
\text { 5a }\end{array}$ & 165000 \\
\hline $\begin{array}{l}\text { Scenario } \\
\text { 5b }\end{array}$ & 119000 \\
\hline
\end{tabular}

(a)

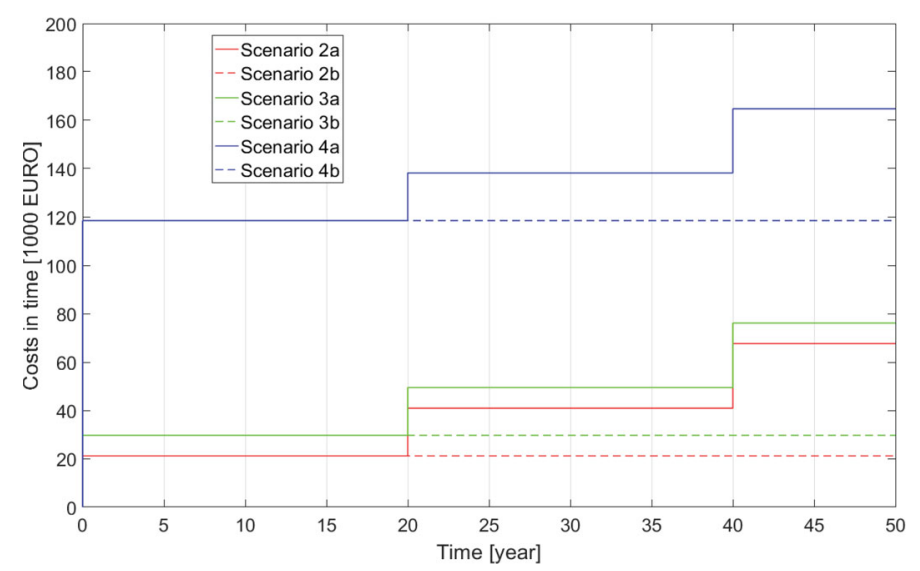

(b)
Fig. 10: Financial costs in the future: (a) total financial costs; (b) financial costs over time
102 years, according to the calculations. Scenario 4 gives the longest service life of the bridge. The calculated remaining service life is longer than 300 years. The dependence of coefficients of fatigue damage on time for all scenarios and the approach of linear theory is shown in Fig. 9.

Nonlinear approaches of calculation provide more favourable results than linear approaches (Table 6). The main reason for this is that nonlinear approaches take into account the load interaction effects.

From the bridge owner's point of view, financial costs play an important role in decision making. Costs related to all considered scenarios are shown in Fig. 10. On the basis of Table 5, there are zero costs in the case of scenario 1 owing to the absence of maintenance works. On the other hand, scenario 4 ensures the longest service life; however, the costs are the highest for the owner. An approach taking into account the NPV was used to compare past and future cash flows with the current ones. The value of the discount rate was set to $0.5 \%$. The inflation rate was taken into account using a value of $2.0 \%$. Figure 10 shows maintenance costs over time.

\section{Conclusion}

This paper presented the methodology developed for the assessment of remaining fatigue life of steel riveted bridge components. FALCom software was developed for automatic calculation of the remaining fatigue life, including the consideration of the current corrosion weakening and corrosion conditions.

The application of the developed methodology was shown in a practical example. The most critical components with respect to fatigue of an old railway steel bridge were assessed and the possibilities for extending the service life of the bridge were analysed.

The following conclusions may be drawn from the case study:

1. The calculated remaining fatigue life of the detail for all scenarios is longer than required. The longest remaining service life is ensured by scenario 4 , where the critical components are replaced.

2. On the basis of the calculations, the bridge may be in service for another 100 years without any maintenance. 
However, there are several uncertainties, such as the development of traffic intensity and the composition of traffic in the future.

3 . In the case where the required service life would be longer than the current 50 years, scenarios 2 and 3 would provide suitable solutions to ensure the efficient fatigue capacity of the bridge. Scenarios $2 \mathrm{a}$ and $3 \mathrm{~b}$ provide a similar remaining service life for approximately the same financial costs.

4. The approach of nonlinear accumulation of fatigue damage provides favourable results from the point of view of length of service life. The values of coefficients of fatigue damage are lower in the case of nonlinear approaches.

5. The developed methodology including FALCom software may be a suitable tool for more accurate evaluation of the current state of historical steel riveted bridges. Finally, the methodology can lead to cost savings, as historic bridges can be in operation for a long time without the need for extensive reconstruction.

\section{Suggestions for Subsequent Research}

The next phase of this research will focus on the optimization of scenarios. The most suitable maintenance procedure for the bridge, with respect to required service life and financial costs, will be evaluated.

\section{Nomenclature}

$c_{R, 50}$
$c_{R, 95}$
$D$
$d$
$d$
$d_{A}$

reduction coefficient reduction coefficient coefficient of fatigue damage material parameter (Eq. (2)) discount rate (Eq. (5)) level of corrosion determined as the change in cross-section area

E $\quad$ Modulus of elasticity

$f \quad$ Morrow's plastic work interaction exponent

$f_{u} \quad$ Ultimate strength

$f_{y} \quad$ Yield strength

$i \quad$ inflation rate

IM financial costs for the maintenance $n_{i}$

$N_{i}$

$N P V$

$\mathrm{N}_{\text {calc, mean }}$ calculated number of cycles (mean value)

$\mathrm{N}_{\text {calc, }} 95 \%$ q calculated number of cycles (95\% quintile)

$\mathrm{N}_{\text {exp }} \quad$ measured number of cycles

$t_{M} \quad$ year of maintenance

$\alpha \quad$ function in the damage model

$\beta$ coefficients of the damage

$\Delta \sigma_{\mathrm{c}} \quad$ original detail category of an

uncorroded sample

$\Delta \sigma_{c, R, 50} \quad$ mean value of reduced detail

category

$\Delta \sigma_{\mathrm{c}, \mathrm{R}, 95} \quad 95 \%$ quintile value of reduced

detail category

$\sigma_{i} \quad$ the $i^{\text {th }}$ load stress level

$\sigma_{\max } \quad$ maximum stress of multilevel alternating load stress

\section{Disclosure statement}

No potential conflict of interest was reported by the authors.

\section{Funding}

This work was supported by the NAKI II project of the Ministry of Culture of the Czech Republic: "The methods for achieving the sustainability of industrial heritage steel bridges" [grant number DG18P02OVV033].

\section{ORCID}

Martin Macho (D) http://orcid.org/00000001-7894-0607

Jose Matos (D) http://orcid.org/00000002-1536-2149

\section{References}

[1] UIC 778-2-R. Recommendations for Determining the Carrying Capacity and Fatigue Risks of Existing Metallic Railway Bridges Draft. UIC: Paris, 2016.

[2] Methodical Guideline for Determining the Carrying Capacity of Railway Bridges. 2005. SŽDC.

[3] Landolfo R, Cascini L, Portioli F. Modeling of Metal Structure Corrosion Damage: A State of the Art Report. Vol. 2, Sustainability. 2010.
[4] Heinemeyer C, Feldmann M. The influence of rivet corrosion on the durability of riveted connections. Steel Constr. 2011; 4(3): 188-192.

[5] Pipinato A, Pellegrino C, Bursi OS, Modena C. High-cycle fatigue behavior of riveted connections for railway metal bridges. J Constr Steel Res. 2009; 65(12): 2167-2175.

[6] DiBattista JD, Adamson DE, Kulak GL. Fatigue strength of riveted connections. J Struct Eng. American Society of Civil Engineers; 1998; 124(7): 792-797.

[7] Macho M, Ryjáček P, Matos JC. Static and fatigue test on real steel bridge components deteriorated by corrosion. Int J Steel Struct. 2018; 19(1): 110-130.

[8] CAN/CSA-S6-06. Canadian Highway Bridge Design Code. Canadian Standards Association: Toronto, 2012.

[9] Kulicki JM, Prucs Z, Sorgenfrei DF, Mertz DR. Guidelines for Evaluating Corrosion Effects in Existing Steel Bridges. National Cooperative Highway Research Program, Report No. 333, 1990.

[10] Lv Z, Huang H-Z, Zhu S-P, Gao H, Zuo F. A modified nonlinear fatigue damage accumulation model. Int J Damage Mech. 2015; 24 (2):168-181.

[11] Miner MA. Cumulative damage in fatigue. $J$ Appl Mech. 2014; 12: 159-164.

[12] Corten HT, Dolan TJ. Cumulative fatigue damage. Proceedings of the International Conference on Fatigue of Metals, Institute of Mechanical Engineering, London, 1956: 235-246.

[13] Morrow DJ. The effect of selected subcycle sequences in fatigue loading histories. Random Fatigue Life Predictions. ASME. 1986; 72: 43-60.

[14] Dattoma V, Giancane S, Nobile R, Panella FW. Fatigue life prediction under variable loading based on a new non-linear continuum damage mechanics model. Int J Fatigue. 2006; 28(2):89-95.

[15] Guedes Soares C, Garbatov Y. Reliability of maintained, corrosion protected plates subjected to non-linear corrosion and compressive loads. Marine Structures. 1999; 12:425-445.

[16] Klinesmith DE, McCuen R. Albrecht P. Effect of environmental condition on corrosion rate. J. Mater. Civil Eng. 2007; 19:121-129.

[17] Žemličková L, Rotter T. Equivalent constant amplitude stress range of railway bridges. Dissertation work, ČVUT Praha, 2004.

[18] Frýba L. Dynamics of Railway Bridges. Academia: Praha, 1992.

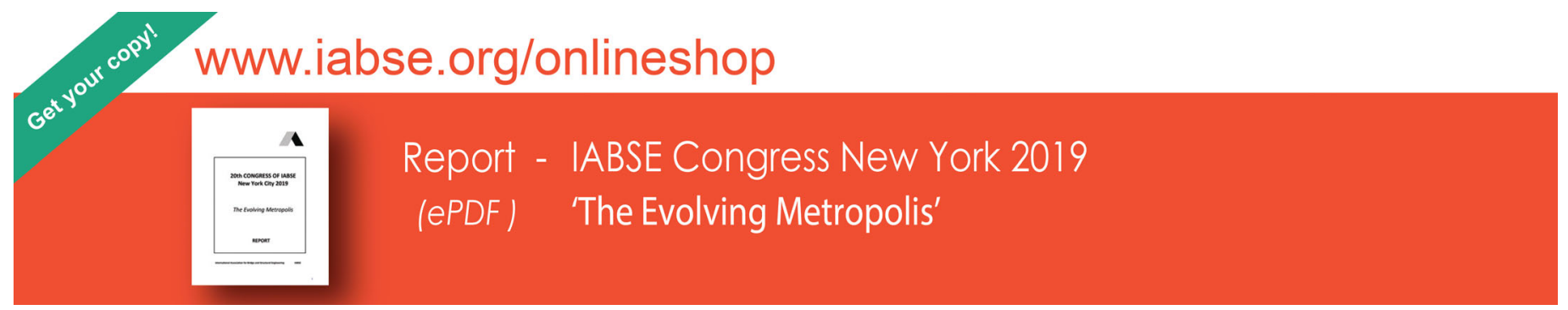

